\title{
CUIDADO PRESTADO PELO ACADÊMICO DE ENFERMAGEM EM UNIDADE DE TERAPIA INTENSIVA NEONATAL NA ÓTICA DA MÃE ${ }^{1}$
}

\author{
THE MOTHER'S VIEW ON THE ASSISTANCE GIVEN BY ACADEMICS OF \\ NURSING IN A NEONATAL INTENSIVE THERAPY UNIT \\ EL CUIDADO PRESTADO POR EL ACADÉMICO DE ENFERMERÍA EN LA \\ UNIDAD DE TERAPIA INTENSIVA NEONATAL
}

Sandra Teixeira de Araújo Pacheco ${ }^{2}$
Elizabeth Ranier Martins do Valle ${ }^{3}$

RESUMO: Este estudo buscou compreender o que significa para a mãe o cuidado prestado pelo acadêmico de enfermagem a seu filho na unidade de terapia intensiva neonatal. A pesquisa, de natureza qualitativa, teve como suporte a abordagem fenomenológica. Foram entrevistadas dez mães, cujos filhos recém-nascidos estavam internados em uma unidade de terapia intensiva neonatal localizada na cidade do Rio de Janeiro. A interpretação tendo como suporte filosófico o pensamento de Martin Heidegger, expresso na sua obra Ser e Tempo I, permitiu desvelar que para o ser-mãe, o acadêmico de enfermagem ao cuidar de seu filho, mostrou-se como um ser-ai solicito. As mães reconheceram neste cuidar uma relação de encontro, no qual o aluno pre-ocupou-se com o que fazia e com quem fazia, assumindo assim um modo autêntico de cuidar.

PALAVRAS-CHAVE: Enfermagem, unidade de terapia intensiva neonatal, Fenomenologia

\section{MINHA TEMPORALIDADE E ESPACIALIDADE PROFISSIONAL}

Em 1994 iniciei minhas atividades docentes, orientando e supervisionando alunos da disciplina de Estágio Supervisionado em Enfermagem Neonatal do curso de Graduação de uma Faculdade de Enfermagem do Estado do Rio de Janeiro. O estágio supervisionado era oferecido sob a modalidade de internato e ocorria num periodo correspondente a 23 dias. Os internos de enfermagem prestavam cuidados a recém-nascidos na unidade de terapia intensiva e no berçário de cuidados intermediários.

Inicialmente, todo o grupo de alunos permanecia no berçário intermediário por um periodo de 3 a 4 dias, com o objetivo de familiarizar-se com a rotina de atendimento específico daquela unidade para começar a prestar cuidados ao recém-nascido.

Após este periodo, o grupo se subdividia passando, parte dele, a desenvolver atividades na unidade de terapia intensiva e a outra parte continuava a prestar cuidados aos neonatos no berçário intermediário, em função de não se poder manter mais de 3 alunos na unidade de terapia intensiva, devido ao pequeno espaço físico da mesma. UERJ.

'Recorte da Dissertação de Mestrado apresentada ao curso de Pós-Graduaçāo da FENF/

${ }^{2}$ Autora da Dissertação. Mestre em Enfermagem. Professora Assistente do Departamento de Enfermagem Materno-Infantil da Faculdade de Enfermagem da UERJ.

${ }^{3}$ Psicóloga e Livre Docente aposentada do Departamento de Enfermagem Psiquiátrica e Ciências Humanas da Escola de Enfermagem de Ribeirāo Preto, Universidade de São Paulo.

4 Doutora em Enfermagem. Professora Adjunto do Departamento de Fundamentos de Enfermagem e Administração da EEAAC/UFF. 
Em ambas as unidades neonatais, os alunos assumiam integralmente os cuidados com os recém-nascidos. É importante ressaltar que ao assumir esses cuidados, eu, enquanto educadora, procurava orientar o aluno para um cuidar que não deveria estar voltado somente para as questões técnico-cientificas, mas também para as questões humanas daquele ser que estava sendo cuidado. Neste sentido, entendendo que a familia fazia parte do contexto, procurava favorecer a interação do aluno com ela, solicitando-lhe, por exemplo, que estimulassem as mães a frequentar a unidade de terapia intensiva com o objetivo de familiarizá-las com aquela situação, visando promover, assim, o início do desenvolvimento da relação de apego entre a mãe e seu filho.

Apesar de utilizar tais estratégias no ensino, pude constatar durante estes anos que alguns alunos de enfermagem, ao cuidarem do recém-nascido em unidade de terapia intensiva, acabavam direcionando sua atenção para as questões patológicas do neonato e para todo o aparato tecnológico que envolvia aquele cuidar.

Percebi que alguns apresentavam uma certa dificuldade em interagir com as mães dos recém-nascidos. Eles ficavam tão envolvidos com os procedimentos técnicos e com toda a tecnologia empregada, que muitas vezes não se davam conta da presença dos familiares próximo ao bebê. Neste sentido, alguns alunos consideravam no seu cuidar apenas o recémnascido, não conseguindo reconhecer a mãe do bebê como sendo também um dos focos de atenção de seu cuidado.

Percebi, também, que algumas mães demonstravam insegurança, medo e preocupação quando os alunos de enfermagem prestavam cuidados a seus filhos gravemente enfermos. As vezes esse comportamento era explicitado verbalmente para determinados membros da equipe ou de forma não verbal, pela expressão do olhar e dos gestos.

Em outros momentos verifiquei situação totalmente oposta, ou seja, mães que demonstravam satisfação quando seus filhos eram assistidos pelo acadêmico de enfermagem, chegando inclusive a solicitar a permanência do mesmo no cuidado com o recém-nascido. Isso se dava principalmente em situações em que o aluno interagia efetivamente com as mães, explicando-lhes os cuidados que estavam prestando e incentivando-as a participarem desse momento.

Estas situações ocorridas ao longo do meu exercicio docente, fez-me refletir sobre a prática assistencial do acadêmico junto ao recém-nascido grave. Assim, hoje venho me preocupando em como vem se dando esse cuidado, segundo a vivência das mães, ou seja, que significado tem esse cuidado para elas? Como acontece o processo de interação do aluno com essas mães?

Portanto, a partir de tais inquietações, este estudo teve como objetivo compreender os significados atribuidos pelas mães ao cuidado prestado pelo acadêmico de enfermagem a seu filho na unidade de terapia intensiva neonatal.

\section{CONDUÇÃO DO ESTUDO}

\section{A ABORDAGEM FENOMENOLÓGICA}

Este estudo é de natureza qualitativa, tendo como suporte a abordagem fenomenológica. Estudiosas no assunto como Boemer (1994) enfatizam que a Fenomenologia tem a preocupação de descrever o fenômeno e não de explicá-lo. Desta forma, este método de investigação não se preocupa com o buscar das relações causais.

A Fenomenologia caracteriza-se por uma preocupação em descrever a realidade como é vivida pelo sujeito da experiência.

$\mathrm{Na}$ tentativa de compreender o significado atribuido pelas mães ao cuidado prestado pelo acadêmico de enfermagem a seu filho, na unidade de terapia intensiva neonatal, aproprieime do pensamento de Martin Heidegger uma vez que ele estudou a existência humana, 
aproximando-se do cotidiano e da experiência concreta do vivido, desvelando os modos de serno-mundo.

A ontologia Heideggeriana vai se interessar pelo cotidiano e defender que a partir do diaa-dia é que se chega aos problemas fundamentais (HEIDEGGER,1981). Assim, tentando aproximar-se desses problemas utiliza-se de expressões como ôntico, ontológico, existenciário e existencial, e segundo o mesmo pensador: "Ontológico são as várias formas de algo se tornar manifesto, realizado." (ibid., p. 11).

Existência vem do verbo ek-sistere; ek-sistência, portanto é algo que emerge, se manifesta, ou seja, que se desvela. Para o citado autor somente o homem pode "existir" pois apesar deste ser um ente no mundo, bem como as coisas, somente ele é dotado de pre-sença, é Dasein, é ser-aí, enquanto que as coisa são entes com quem mantemos uma relação de "ocupação": ôntico é tudo que é percebido, entendido, conhecido de imediato" (ibid., p. 11).

Assim como Heidegger chamou existencial ao ontológico, ele também chamou existenciário ao ôntico. Este filósofo partiu da vida cotidiana para mostrar os fenômenos ônticos e seus aspectos ontológicos.

As caracteristicas ontológicas do ser humano (ser-ai, Dasein) são também chamadas existenciálias, ou seja, características ontológicas da existência.

Para Heidegger o homem não é uma coisa entre outras, ele é ser-ai, num sentido auto localizado e auto consciente, numa relação constante com os objetos, com as pessoas e com as situações (ibid., p. 33).

Buscando compreender a existência do ser do humano, na sua dimensão ontológica , Heidegger considera o ser-ai como: ser-no-mundo e ser-com. Para esse filósofo a expressão ser-no-mundo não é apenas uma simples presença em meio à natureza, é a relação entre todos os entes envolventes e não envolventes ao redor daquele que vivência uma experiência.

Reforçando este pensar, Martins e Bicudo (1989, p.80) referem que: "onde quer que o Ser esteja presente, na sua realidade vivida haverá mundo, porque a própria existência humana é estar-no-mundo, portanto Ser e mundo formam uma totalidade".

Já a expressão ser-com está ligada às várias formas que o existir humano está possibilitado a viver com-os-outros, já que o homem só está no mundo porque está junto de alguém ou de alguma coisa (HEIDEGGER,1981).

\section{A TRAJETÓRIA DAPESQUISA}

Elegi como campo de estudo uma unidade de terapia intensiva neonatal de um hospital universitário do municipio do Rio de Janeiro, onde iniciei a obtenção dos depoimentos, após autorização do Comitê de Ética e Pesquisa.

As depoentes da pesquisa foram 10 mães de recém-nascidos cuidados pelos acadêmicos.

Antes de qualquer aproximação com as mães, procurei me familiarizar com a situação clínica dos recém-nascidos, através da leitura de prontuários. Nesta leitura, verifiquei quais tinham sido os recém-nascidos cuidados pelos alunos, pelo periodo mínimo de três dias. Posteriormente entrei em contato com essas mães agendando um encontro.

Para a obtenção dos depoimentos realizei entrevistas na modalidade fenomenológica, sendo as mesmas gravadas com o consentimento das mães utilizando a questão orientadora: O que foi para você o cuidado prestado pelo acadêmico de enfermagem a seu filho?"

Após a entrevista agradeci a cada mãe e, durante as transcrições, voltava meu olhar atento às suas palavras, ao modo como se mostraram em sua singularidade.

\section{ANÁLISE DOS DEPOIMENTOS}

Para a análise das descrições utilizei o direcionamento indicado por Martins e Bicudo (1989), acerca de como se conduzir uma análise sob o enfoque fenomenológico. 
Inicialmente fiz uma leitura das descriçöes, do inicio ao fim, com vistas a obter um sentido do todo. Neste momento, não busquei qualquer interpretação, mas apenas o sentido do geral expressado pelas mães. Num segundo momento, foi necessário reler as descrições várias vezes para entender o que as mães desejaram expressar. Nesta etapa, procurei fazer várias anotaçōes às margens das transcrições, na tentativa de apreender os significados.

Uma vez apreendidos os significados atribuidos pelas mães em cada descrição, voltei para os depoimentos, agora procurando construir as unidades de significações, dentro de minha perspectiva enquanto enfermeira/professora, levando em conta a interrogação original.

A construção das unidades de significados mostra a visão das mães sobre os significados atribuidos por elas ao cuidado prestado pelo acadêmico de enfermagem a seu filho na unidade de terapia intensiva.

\section{A COMPREENSÃO: AS UNIDADES DE SIGNIFICADOS}

$\mathrm{Na}$ ótica da mãe o acadêmico de enfermagem, ao cuidar de seu filho na unidade de terapia intensiva neonatal:

- Interage com ela, esclarecendo-a sobre a saúde e os cuidados prestados a seu filho.

As falas das mães expressaram que foi durante o relacionamento graduando-mãe, que elas se sentiram à vontade para saberem sobre o estado de saúde e os cuidados que estavam sendo prestados a seus filhos.

(...) A aluna me explicava as coisas... Ela falava que eu podia tocar e mexer na minha filha (Amor Perfeito)

(...) Eles me passavam tudo que faziam com minha criança...eles me explicavam o porque que estavam fazendo isso, porque que estavam fazendo aquilo. (Papoula)

- Faz com que ela sinta-se valorizada, segura e confiante com seu atendimento.

Os alunos mostraram-se sensiveis, estabelecendo com as mães uma relação de abertura e de amizade e estas reconheceram e valorizaram os cuidados prestados pelos alunos. Tal valorização se deu não só pela capacidade profissional demonstrada, como também, pela maneira como eles desenvolviam tais cuidados. Modos esses exemplificados por elas como: delicado, tranqüilo, atencioso e carinhoso.

(...) Eles cuidavam da minha criança demonstrando e me passando segurança, ou seja eles me deixavam bastante tranqüila. (...) eles foram muito dedicados. A M__ (bebê) foi muito bem cuidada por eles. Os alunos são bastante capacitados, apesar de ainda estarem estudando.(Papoula.)

(...) Pra mim o cuidado delas foi muito importante, eu fiquei muito satisfeita com as alunas que cuidaram dos meus filhos. (Girassol.)

\section{(...) pra mim o cuidado das alunas foi muito importante. (Cravo)}

- Amplia seu cuidado também a ela, despertando-lhe sentimentos de afeto e companherismo.

Segundo as mães, os cuidados prestados pelos graduandos foram estendidos também a elas, pois se sentiram amparadas, protegidas e apoiada, durante a internação de seus filhos naUTI.

Em suas falas emergiu também a gratidão pela maneira companheira, amiga e afetiva 
demonstrada pelos alunos a cada uma delas, durante a realização desse cuidado.

(...) Então a aluna que cuidou da minha filha, não cuidou apenas dela, mas eu posso dizer que ela cuidou também de mim. ..para mim ela deu o apoio que eu tanto precisava. (Violeta)

(...) Eu passo a semana sozinha, então na hora das visitas quem me fazia companhia eram elas, as alunas que ficavam conversando comigo(...) elas foram como uma segunda familia para mim. Eu passava para elas coisas que eu não tinha para quem contar. E elas me passavam calma...amizade(...) Poxa! Se as alunas tivessem noção de como a força delas assim... a companhia delas foi importante para mim. (Margarida)

\section{setor}

- Mostra-se atencioso e carinhoso e, neste fazer se diferencia do profissional do

Revelaram que, no cuidar, os alunos se mostraram próximos a elas, ajudando-as com seus filhos sempre que necessário.

(...) o profissional, ele é profissional, ele não mistura sentimentos. Ao contrário dessas alunas, elas são sentimentalissimas, elas estão fazendo aquilo que a profissão manda, porque tem que fazer...mas totalmente com sentimentos( copo de leite)

(..)Eu acho que as estagiárias parece que tem mais cuidado, mais carinho...(...) Então, as alunas que estavam estagiando mesmo, quando eu chegava, elas estavam perto da minha filha... me ajudavam com minha filha. Já a que era profissional, fez aquilo tudo comigo(...) então eu passei duas situações horriveis aqui e não eram com as estagiárias, pelo contrário, as estagiárias forma muito atenciosas.(...)porque tudo de ruim que eu estou passando, eu estou passando com um profissional e não com o estagiário (margarida).

Desta forma, perceberam diferenças entre o modo de cuidar do aluno e o modo de cuidar do profissional de enfermagem que trabalhava no setor. Para as mães, o fato de os alunos estarem se iniciando na profissão e a vontade que eles têm de aprender, podem ser os possiveis motivos que os levaram a cuidar de modo diferenciado do profissional.

\section{A INTERPRETAÇÃO}

Para chegar à interpretação do objeto de estudo investigado, tendo como subsidios a compreensão vaga e mediana, fundamentei-me no pensamento de Martin Heidegger (1993), a partir de sua obra Ser e Tempo I.

Segundo Simões (1995, p.29) a fase de interpretação permite: "a compreensão ou aclaramento dos sentidos e significados atribuidos pelos depoentes e consequentemente $o$ desvelar da coisa em si".

É importante ressaltar que o desvelamento do fenômeno proporciona diferenciar o que parece do que realmente é. A busca do que é em si mesmo, na verdade, é a busca da apreensão do sentido. Esta apreensão não é uma verdade única ou última, porque no movimento de desvelamento como possibilidade do método fenomenológico heideggeriano, não se consegue apreender o fenômeno como um todo e sim, algumas facetas dele (ABREU; SOUZA, 1999). O fenômeno nunca é desvelado totalmente, e sim, em sua totalidade.

Então, a partir das unidades de significação, tentei ultrapassar os aspectos ônticos verbalizados pelas mães acerca do cuidado prestado pelo acadêmico de enfermagem ao seu filho, para alcançar o sentido desse cuidar.

Na concepção de Heidegger (1993, p.208), sentido é: 
...aquilo em que se sustenta a compreensibilidade de alguma coisa... aquilo que pode articular-se na abertura da compreensão... Na medida em que compreensão e interpretação constituem existencialmente o ser do pre, o sentido deve ser concebido como o aparelhamento existencial-formal da abertura pertencente à compreensão.

Assim, na busca de clarear o sentido, compreendi, pelo que emergiu nas falas das depoentes, que ao cuidar o aluno se mostrou como Pre-sença, Dasein, como ser-ai.

Para Heidegger (1993), a pre-sença compreende-se a partir da sua própria existência. A existência refere-se ao próprio ser com o qual a presença pode se comportar desta ou daquela maneira. A existência é, então, a maneira do homem ser no mundo, diferente do modo de ser dos entes simplesmente dados.

$\mathrm{O}$ acadêmico de enfermagem, como pre-sença, existindo em sua cotidianidade, mostrouse lançado no modo ontológico da disposição. A pre-sença no modo constitutivo da disposição é sempre um ser-lançado, isto é, um ser que está aberto a todas as possibilidades. (ibid., p. 46).

O graduando, como um ser lançado, se mostrou aberto para aprender a cuidar dos recém-nascidos em uma unidade de terapia intensiva neonatal. Nesta disposição, evidenciouse a abertura para o outro, ou seja, para as mães dos bebês. Por ser próprio da pre-sença sercom-os-outros, o cuidado desse aluno foi então, manifestado pela afetividade.

O acadêmico, ao cuidar do recém-nascido e de sua mãe, mostrou-se aberto para a sua possibilidade de ser-no-mundo-com. Ao manter uma relação empática com as mães, o graduando mostrou que se importava com elas e que estava aberto para ouvi-las, ou seja, que estava aberto para compreender o poder-ser delas.

Para Heidegger (1993), há duas formas distintas de envolvimento do homem com o mundo, denominadas de "solicitude". Nestas, o ser pode ocupar-se com entes envolventes e preocupar-se com entes dotados do ser da pre-sença. O se ocupar não é uma característica ontológica do ser-com, mas sim um modo de ser da pre-sença para com os entes que vêm ao seu encontro no mundo da ocupação. Já a pre-ocupação é uma caracteristica ontológica da pre-sença enquanto ser-com (CAMARGO,1997).

A preocupação no que se refere a seus modos de convivência, possui duas possibilidades extremas: a primeira é "fazer pelo outro", tornando o outro dominado e dependente, afastandoo de si mesmo. A segunda é propiciar a possibilidade do outro ser; neste modo, o cuidado é devolvido ao ser como tal, ajudando-o a tornar-se livre para assumir a responsabilidade por si mesmo e suas possibilidades mais próprias Heidegger (1981).

Assim, enquanto ser-ai-com-o-outro, o cuidado do aluno aconteceu no modo da preocupação, pois existiu por parte dele uma pre-ocupação com o que fazia e com quem se fazia. Por outro lado, este estudo possibilitou-me apreender que, de certo modo, o relacionamento mantido entre os profissionais de enfermagem da unidade de terapia intensiva neonatal e as mães dos recém-nascidos se deu no modo da impessoalidade. Ao se mostrar distante dessas mães, imersas no mundo da terapia intensiva, a equipe de enfermagem manteve-se aberta para a possibilidade de ser-no-mundo-com-o-outro no modo inautêntico. Ocupando-se, apenas, com a manualidade do assistir, não levou em consideração a mãe como sujeito desse cuidar.

O ser-ai-profissional disperso nessa impessoalidade, encontrou-se, então, no modo de ser do cotidiano. Em seu cuidar inautêntico, impessoal e ocupado, não conseguiu perceber as necessidades das mães e dos recém-nascidos, tratando-os assim como entes simplesmente dados.

Para Heidegger (1993, p.182) : “O próprio da pre-sença cotidiana é o próprio-impessoal que distinguimos de si mesmo em sua propriedade...Enquanto o próprio-impessoal, cada presença se acha dispersa na impessoalidade, precisando ainda se encontrar". Já o acadêmico de enfermagem, enquanto presença, implementa um cuidar baseado na preocupação, assumindo neste, o recém-nascido e sua mãe como co-presenças que lhe vem ao encontro no mundo do 
aprender/cuidar.

\section{CONSIDERAÇÕES FINAIS}

A realização do presente estudo permitiu-me ter um outro olhar sobre o cuidado prestado pelo acadêmico ao recém-nascido e sua mãe. Penso que possibilitou despertar a atenção de nós, docentes e profissionais de enfermagem, para a reflexão a respeito de como é percebido o cuidado pelos clientes.

Despojando-me de pressupostos para que faces do fenômeno se mostrassem como tal em si mesmo, compreendi nos significados atribuidos pelas mães, que o cuidado prestado pelo acadêmico de enfermagem foi manifestado pela consideração a ela e ao seu filho enquanto seres-ai, em suas possibilidades. Em seu modo de ser, o aluno reconheceu e demonstrou respeito pelo direito da mãe em participar do cuidado ao seu filho, percebendo isto como fator benéfico para a saúde do recém-nascido. Neste sentido, emergiu no modo de cuidar do graduando um olhar atentivo para com o ser-do-outro.

Acredito que esse cuidar atentivo demonstrado pelos alunos de enfermagem para com os recém-nascidos e suas mães na unidade de terapia intensiva, pode estar sendo reflexo da nova abordagem curricular adotada pela Faculdade de Enfermagem, que vem privilegiando na formação desses acadêmicos, um novo olhar para o cuidar/cuidado em enfermagem.

Nessa abordagem, o "processo" de cuidar vem sendo refletido junto aos alunos, não simplesmente como um fazer de tarefas, mas como um compartilhar de vivências, no qual o cliente é compreendido como sujeito singular. Assim, procuramos considerar nesta abordagem, um cuidar voltado para os aspectos humanos que vão além do atendimento focalizado apenas nas necessidades biológicas de cada cliente.

Temos buscado, dessa maneira, resgatar junto ao aluno, a possibilidade de um cuidado atento para o ser do humano e não apenas para um corpo circunstancialmente doente.

Por outro lado, esse cuidar atentivo demonstrado pelos acadêmicos pode ser ainda devido ao fato de que, não estão inseridos no contexto institucional, como os profissionais de saúde, que ali estão no modo do cotidiano, e deste modo os alunos se mostraram como seres abertos aos outros seres-ai.

Assim, a partir do cuidado prestado pelo aluno, pude perceber o quanto é importante e necessário continuarmos a enfatizar na formação acadêmica do enfermeiro, um cuidar que contemple a existência humana, ou seja, um cuidar que considere o outro (cliente) como abertura, um cuidar que permita que os envolvidos (aluno-cliente) se revelem em suas possibilidades de ser. Enfim, um cuidar que possibilite o envolvimento entre quem cuida e quem é cuidado.

Creio que nesta direçäo, o aluno continuará cuidando de modo autêntico, possibilitandoo ser-com-o-outro-no-mundo da unidade de terapia intensiva neonatal. Ser-com-o-outro autenticamente, na perspectiva do cuidar, é condição fundamental do exercicio profissional, porque é condição ontológica do ser humano (CORRÊA, 2000. p.128).

Acredito que, ao despertarmos na formação acadêmica do enfermeiro essa outra possibilidade de cuidar, o seu agir profissional poderá se tornar distinto do que ocorre hoje, visto que neste sentido, o cuidado não estará reduzido simplesmente à execução de um conjunto de tarefas pré-determinadas, mas estará voltado em primeira instância, para a dimensão do ser humano, no qual aluno - ser humano que cuida coexistirá com o ser humano- cliente - ambos atribuindo sentimentos e significados à experiência vivenciada.

ABSTRACT: The objective of the present study is to investigate the perspective of mothers regarding the care given by academics of nursing to their newborn in a neonatal intensive therapy unit. This is a qualitative research based on a phenomenological approach which has as its philosophical framework 
the thought of Martin Heidegger expressed in his book Being and Time. The data used in the investigation were interviews given by ten mothers who had their newborns in a neonatal intensive therapy unit of a university hospital in the city of Rio de Janeiro. The interpretation of the data collected revealed that mothers viewed the nursing academics as solicitous beings regarding the care given to their newborns. They also acknowledged that these students were engaged in the assistance given and concerned with what was being done and to whom it was being done.

KEYWORDS: nursing, Neonatal Unit of Intensive Therapy, Phenomenology

RESUMEN: El estudio buscó detectar lo que significa para la madre el cuidado que los académicos de enfermeria prestan al hijo recién nacido. La investigación de naturaleza calitativa, basó sus datos en el pensamiento fenomenológico de Martin Heidegger expresado en su trabajo "El ser y el tiempo". El estudio se desarrolló en Rio de Janeiro, de marzo a mayo de 2000. La población-foco estaba constituida por 10 madres, cuyos hijos estaban internados en una unidad neonatal de terapia intensiva. El estudio reveló que para el ser-madre, el estudiante de enfermeria se mostró un solicito ser-ahi, respecto al cuidado con su hijo. Las madres reconocieron en ese cuidado una relación de encuentro, en el que el alumno se pre-ocupó con lo qué hacia y con quién hacia, asumiendo asi un modo auténtico de cuidar.

PALABRAS CLAVE: Enfermeria, Unidad de Terapia Intensiva Neonatal, Fenomenologia

\section{REFERÊNCIAS BIBLIOGRÁFICAS}

ABREU,A.S. G.T.; SOUZA, I.E.O. O pai a espera do parto: uma visão compreensiva do fenômeno. Rio de Janeiro: Aurora, 1999.

BOEMER, M.R. Empatia - proposta de abordagem fenomenológica. Rev. Esc. Enf. USP, São Paulo, v.18, n. 1, 1994. p. 23-29.

CAMARGO,T.C. O ex-sistir feminino num rosto sem moldura - uma análise compreensiva da mulher submetida à quimioterapia oncológica. Rio de Janeiro, 1997. 135f. Dissertação (mestrado em Enfermagem) - Escola de Enfermagem Anna Nery, Universidade federal do Rio de Janeiro.

CORREA, A. K. Do treinamento do enfermeiro à possibilidade da educação em terapia Intensiva: em busca do sentido da existência. São Paulo, 2000. 212f. Tese (Doutorado em Enfermagem) Universidade de São Paulo.

HEIDEGGER, M. Ser e Tempo: parte I. 3.ed. Petrópolis: Vozes, 1993.

Todos nós...ninguém : um enfoque fenomenológico do social. Tradução : Dulce Mara Critelli. São Paulo: Moraes, 1981.

MARTINS, J. ; BICUDO, M. A. V. A pesquisa qualitativa em psicologia fundamentos e recursos básicos. Sāo Paulo: Moraes, 1989.

SIMŐES, S.M.F. O ser parturiente: um enfoque vivencial. Rio de Janeiro, 1995. 95p. Dissertação (Mestrado em Enfermagem )- Escola de Enfermagem Anna Nery, Universidade Federal do Rio de Janeiro.

Recebido em junho de 2001

Aprovado em dezembro de 2001 